\title{
PROCESS ECONOMY AND SERVICE TRANSFORMATION AT DUSK!N IN JAPAN
}

\author{
Marius PROFIROIU ${ }^{a^{*}}$, Hideki ISHIDA $^{b}$, Hiroaki KANEKO $^{c}$, \\ Keita SUGIYAMA ${ }^{d}$, George MOISE ${ }^{e}$ \\ ${ }^{a, b, c, d, e}$ Bucharest University of Economic Studies, Romania
}

\begin{abstract}
This paper illustrates how Duskin is among the leader companies in revenue, profit, and innovation by increasing their focus on more employee experience. The authors of this paper worked directly with other C-Suites, directors, business leaders, executives, organizational architects and talent operators to determine whether leadership actively promotes transparency and ongoing dialogue, whether teams are empowered to decide on the next best action, and whether leaders reward quick failures as much as successes.
\end{abstract}

KEYWORDS: failure, Japan, job satisfaction, management style, motivation, transformation.

\section{DOI: 10.24818/IMC/2021/05.17}

\section{RESEARCH OVERVIEW}

Behavioral Management and Behavioral Economics have attracted extensive executive attention in Asia and, especially, in Japan. In an effort to switch talent management models from a manufacturing, mass-production driven management model, based on enhancing productivity, efficiency and, ultimately, profit, multiple businesses, ranging from financial firms to energy, life science and technology business have chosen over the past few decades to shift to a people and society driven management model focused on purpose, engagement, collaboration, innovation and sustainability. (Amasawa, 2018). As part of this effort to influence employee mindsets and to nurture collaborative organizational cultures into being, businesses have paid special attention to emotional engineering and ontological design processes, in an effort to determine how to best nudge behavior and to accelerate business transformation based on user experience (Fukuda, 2016).

Unlike efficiency and productivity driven automotive manufacturers focused only on improving tact time and considering people to be a mere replaceable "resource" (similar to any technical part or mechanical unit), Japanese organizations have traditionally been focused on nurturing talent in the long term and creating cultures of collaboration and inclusion (Kaneko, 2021). Furthermore, Japanese organizations have historically been focused on developing a sustainable type of leadership, nurturing leaders and people managers with vision and high empathy for their talent populations (Watahiki, 2021).

In recent years, incentivized and encouraged by the Sustainability Development Goals of the World Economic Forum, an increasing number of organizations in Japan have indicated commitment to sustainability and an increasing willingness to participate in a social value co-creation ecosystem with a strong focus on circular economy (Yamaguchi, 2020).

\footnotetext{
*Corresponding author. E-mail address: marius.profiroiu@man.ase.ro
} 


\section{RESEARCH METHODOLOGY}

In an effort to unveil specific business cases of strengthening talent operations and modernizing business functions, our team conducted a survey with business leaders from multiple organizations in Japan, ranging from technology firms to the private sector. We asked whether leadership actively promotes transparency and ongoing dialogue, whether teams are empowered to decide on the next best action, and whether leaders reward quick failures as much as successes.

Only about half of $368 \mathrm{C}$-suites surveyed said that collaboration was basically not valued, and about half of the $\mathrm{C}$-suites said it was not actively promoted. One approach to company culture change championed by $\mathrm{C}$-suites is a program called "Employee Experience. The C-suites we spoke with were mixed on their progress: 54\% reported that they had increased their focus on "Employee Experience" over the past two years. However, C-suites from companies defined as "Reinventor" are leaders in revenue, profit, and innovation, emerged ahead of their peers in these efforts. 7 in 10 CHROs from "Reinventor" say they are increasing their focus on more employee experience.

From the more than 368 participants who took part in the national survey, we used cluster analysis to identify different segments of the organization. As a result, we were able to classify them into three types, named "Reinventors" "Practitioners" and "Aspirationals". Companies classified as "Reinventors" outperformed their peers in both revenue growth and profitability, and also reported being leaders in innovation. They are also directing their resources toward creating new value from their broad network of partners. They are also working ahead of its peers in co-creation and close collaboration with customers and partners. They are characterized by an open culture that fosters the generation of new ideas.

\section{BACKGROUND}

\subsection{Reinventors, Practitioners and Aspirationals}

Mainly, according to the management style, the corporate landscape is divided in two categories: The low-freedom, and the high-freedom companies. The low-freedom ones, or command oriented are common, profitable and, honestly speaking, their managers are terrified of the alternative, since it's rather easy to run a team that they are told. From a traditional manager point of view, it is faster and more efficient to tell them what to do and make sure they deliver.

In the opposite direction, the high-freedom managers have to explain their people why they are doing what they are doing, to debate whether is the right thing to do and not just to allow them to fail, but to encourage failure in the workplace.

Leaders who build this kind of environments become human magnets for the most talented people. "Our most important priority in HR space is finding talent for the future, not just for now. We're focused on the formidable challenge of attracting, developing and retaining employees with skills we haven't yet determined", General Manager, Human Resources, Financial Services, New Zealand.

\subsection{What are the most important initiatives that need to be taken to ensure sustainable business growth?}

While some business leaders have come to realize that the old ways of doing things no longer work, for others, the traditional ways seem to linger on.

Innovation is necessary for sustainable growth. It is people who initiate and drive such innovation. In order to unleash the potential of people, companies have been working to open up their organizations, share more information and delegate more authorities. But even doing so, and on top of that, achieving a rather impossible task, to remove organizational hierarchies, they have not been able to realize the desired growth.

What could be the reason for this? 
The answer is the lack of willingness to take on new challenges, and an inability to take on new initiatives for fear of failure.

\subsection{Success belongs to those who dare to fail}

$71 \%$ of the CEO's we have interviewed see human capital as a key source of sustained economic value. Those days when leaders spoke of putting people first and then treated them like disposable gears are hopefully over. Companies invest in education and training to develop workforce not just to learn the knowledge, and skills required to effectively perform their duties, but to fully understand the company's values. "It is important for employees to see the company's values as a reflection of their own. Values are at the core of the social contract between company and employee.", Wichian Mektrakarn, CEO, AIS.

But learning is a long and complex process. And the most intuitive leaders never forget that learning is that road to success paved with the most failure of all. $73 \%$ of the CEO's from companies defined as Reinventors have a culture that values failure and success equally in new challenges.

\section{DUSK!N}

Established in February 1963, with a capital stock of 11.3 billion yen (as of March 31, 2021), Duskin embraced the franchise system early in Japan. The company didn't settle just to establish a franchise business, it has been on a continuous search for franchise business opportunities in its afterwards business developments. Currently, their businesses range from environmental hygiene to food service, containing fields such as rental of cleaning tools, professional cleaning services, and food services.

\subsection{Management Philosophy}

Based on their founder's philosophy, kept on to this day, attentive care for the customers is their ultimate focus. His life principles are reflected in their management philosophy called Prayerful Management.

Here is the Duskin Philosophy, a philosophy of sharing joy and doing your best in all that you do that all of Duskin employees incorporate in everyday life:

"Day after day, beginning with today both you and I have a chance to begin our lives anew.

Whether our lot today be profit or loss, be spiritually ready for loss.

As a planter would, let us plant the seeds of joy to every person we meet each day.

For everyone, for you and me, may we live our lives in this world to the fullest realizing our maximum spiritual and material potential."

Duskin's founder, Seiichi Suzuki believed that profit is the reward of light-hearted transactions, putting all the energy to achieve that goal. Happiness might look like an impossible illusion, but he truly believed that people who are taking part in Duskin's work would attain it. Dusting without water also seemed an impossible dream, until Home Duskin - a modern, specially treated cloth came along and brought the founder's wishes one step closer to realization. People called it "the magic dust cloth" and marked the beginning of a new way of cleaning homes across Japan.

Before helping people cleaning home dust, Duskin got rid of a "dusty" way of thinking business, and shaped a franchising system where franchisor and franchisees share in each others's fortunes and grow together. They provided people aligned with their philosophy of Prayerful Management opportunities to turn dust control into a successful business. Their belief: "franchising is a way of life" states strongly that franchising means success both in business and in life.

But not everything that is old has to be changed. Doing good in the world, encouraging compassion and kindness in people, these are values that Duskin and everyone associated with the company commit to stand by. Times are in constant change and along with them the human needs. The only 
way to keep pace with them is changing the products, services and business models. Keeping the balance between what must be kept unchanged and what must be changed is a skill that Duskin seems to manage successful over the years.

\subsection{Human Resources}

Duskin believes that the essential for business growth are enthusiastic employees, motivated every day. The company has programs and structures in place to support this approach, as well as a system for permanent promotion that improves career options for highly talented and motivated employees, as well as a re-employment scheme for required retirees. In this way, an environment is established in which employees can fully utilize their skills and experience.

Hataraki-san, which translates to "those who make things easier for others," refers to all employees. The Hataraki-san concept integrates Duskin's Prayerful Management philosophy. Employees who go above and beyond for others without regard for personal convenience are admired by others and feel more accomplished and fulfilled in life.

To continue Sowing the Seeds of Joy for people and communities, Duskin feels that striking a balance between work and home life is critical for employees' wellbeing. As a result, they have implemented a variety of measures to reduce long work hours and create comfortable environment, with the goal of keeping total work time per employee below 1,850 hours per year.

Duskin has a system in place for qualified non-career employees to transition into permanent career positions. Starting in FY2016, a new "area-specific specialist" course with limited transfers or changes within specific geographic areas was added to the permanent career category, increasing opportunities for permanent career positions. In order to better leverage their human resources, they improved the system that allows area-specific specialists to switch to the "area-specific career track" or "career track" within the permanent career category in FY2018.

The government is implementing programs to encourage elderly adults to join in the labor market as a result of Japan's dropping birthrate and growing aging population. The efforts include recruiting people up to the age of 70 to alleviate labor shortages and ensure the social security system's longterm viability. Duskin is running a program that allows people to re-enter the workforce after reaching the required retirement age of 60 . Those personnel are typically invited to continue working in the department where they worked when they retired. This technique takes advantage of their knowledge and allows them to demonstrate their abilities while also sharing it.

It is critical for companies to create workplaces where women can grow and demonstrate their abilities to their full potential in order to increase their company value and vitality by harnessing varied human resources. Women's opinions are vital for designing and offering products and services, as well as for the company's business growth, because many of Duskin's consumers are women.

In light of this, Duskin created a second action plan that will run from FY2019 to FY2021, in compliance with the Act to Promote Women's Participation and Advancement in the Workplace. They've started programs to encourage women's career development and foster an inclusive corporate culture and work environment as part of the goal. In addition, Duskin has established a numerical objective of raising the ratio of women in management positions to at least $10 \%$.

House cleaning and assistant services are in high demand as the number of two-income families and one-person households rises. With the growing need for everyday help for elders in Japan's superaging society, demand for these services is likely to grow even more.

After getting clearance as a specified organization for the Project to Accept Foreigners Conducting Housekeeping Services in National Strategic Special Zones from the Kanagawa, Osaka, and Tokyo governments in April 2017, Duskin began hiring non-Japanese staff. At the conclusion of FY2019, 47 Filipino citizens had been hired in 12 locations across three prefectures. Following training, these employees provide services at customers' homes. 
Corporations, according to Duskin, have a social obligation to provide work possibilities to individuals with impairments. These job chances should be tailored to the applicants' abilities. They are examining the types of employment fit for the different range of skills and interests of individuals with disabilities and establishing a structure to help them in order to provide more job opportunities with improved retention rates. They continue to actively promote the hiring of people with impairments, with the goal of reaching a 3 percent or higher percentage of disabled employees at Duskin (non-consolidated).

Duskin provides a variety of educational and training opportunities to help employees completely grasp the philosophy of Prayerful Management and apply it to their daily work. They conduct levelspecific training for staff, including new hires, to educate the knowledge and skills needed to properly perform their tasks; they also train Area Managers, who support and stimulate the franchise network. Duskin also encourages employees to advance their careers by obtaining officially recognized qualifications and enrolling in correspondence courses.

\subsection{Duskin and failure culture}

Mon-Chan is the shortened form of the expression Mondai-chansu (問題チャンス), which could be translated as Problem Opportunity. Duskin created an entire culture around this concept, which is seen as an unique trigger to cultivate a better environment that leverage failures.

At Duskin, a problem is rather an opportunity no one noticed, than a source for blunders. Therefore, instead of being blamed, criticized more than necessary, being devalued, labeled as a loser and not being able to be trusted with your work, the employees are all asked to tell their own story with their original insights gained from your failure for more successful customer experience.

In Mon-Chan culture are encouraged failures that no one has experienced before and people who fail are recognized as the ones who identified the potential risk. Moreover, people who haven't created "Mon-Chan" are not evaluated well - it means they are not being challenged. The MonChan approach to failure fosters the employees' autonomy and challenges them to think and act on their own.

"Enhancing the capabilities of our employees is a key factor for our group's competitiveness. We must leverage the strengths of those with various backgrounds to generate new value and achieve sustainable growth." Hashimoto, Chief HR Officer, Duskin

Four steps of Mon-Chan

1. Reflect

Do not ignore failures, but deeply reflect on why they happened and find ways to apply them.

2. Review

Share the insights you have gained with others and provide opportunities for dialogue to further apply them.

3. Prepare

Apply the insights gained from others to your preparation before starting on your own work.

4. Act

Never be afraid to make mistakes or blunders and work to the fullest in order to fully address the expectations from customers.

\section{CONCLUSIONS}

It is possible to foster an innovative organizational culture in an environment of continuous disruptive change, if two conditions are met: fostering a culture of openness with an inclusive "Growth Mindset", and making learning personal and perpetual.

Foster a culture of openness with an inclusive "Growth Mindset":

Listen for impact. 
Nudging behavior is more than efficient in the process of organizational transformation. Using suggestions and positive reinforcement, rather than „top-down” instruction and enforcement has the magic power to change the existing corporate culture to achieve a competitive advantage. „Healing comes from within" is an old saying. Starting from the core of the organization - the individual, as a self-driven transformation, nudging behavior it becomes all the more a sustainable policy. To be fully efficient, nudging behavior needs a nurturing climate designed for the optimal employee experience. And second, in order for the transformation to propagate from the individual towards the organization, managers needs to continuously listen to their people.

Dare to experiment

Strategy has to be updated regularly. Also, multiple pilot tests need to be conducted to ensure both failure and success. The key is to remember that organizations are as unique as their employees.

In the special case of Duskin, behavioral nudging was backed-up by a cultural transformation based, nonetheless on the tradition and the legacy of the company.

Mind the gap

If we wish to alter people's behavior in a particular direction, it's more effective to encourage positive choices rather than restricting unwanted behavior with sanctions. Therefore, the methods used to evaluate and measure success have to be reconsidered: failures must be added as ,units of measurement" of success, because there is a lot of resourceful learning in them. The company has to stay in synchronicity with the leadership team on all matters related to the employee experience and to provide direction and collaboratively set goals.

Make learning personal and perpetual:

Design for the moment

In order to confer a sustainable feature to the cultural transformation, a growth mindset has to be implemented inside the organization. Strategy thinkers need to constantly elicit feedback, coaching and mentoring, while enabling the team to move agile and co-create. In the same time, organization must keep existing HR policies and systems that support employees on track in real time.

Go for gold

Besides creating the favorable climate - an environment where everyone can become a value performer for the customer - organizations need to develop modern tools that support individual, tailor-made learning and resort to intellectual curiosity of the employee. Organizations need to provide ongoing learning opportunities to help their people get there and learning materials available digitally anywhere, anytime.

\section{REFERENCES}

Amasawa, E., Suzuki, Y., Moon, D., Nakatani, J., Sugiyama, H., Hirao, M. \& Fukuda, I. (2018). Designing Interventions for Behavioral Shifts toward Product Sharing: The Case of Laundry Activities in Japan. Sustainability, 10, 2687; doi:10.3390/su10082687.

Fukuda, S. (2016). The next stage of engineering: from how and what to why. Japanese Integrated Design Process Science, 20(2): 5-16.

Kaneko, H., Vlad, C., Gatan, L., Tahakashi, T. \& Adachi, S. (2021). Ina Food Industry: A Company That Makes Employees Happy. Studia Negotia, LXVI(1), 49-77.

Watahiki, N., Chua, JR., Gatan, L. \& Vlad, C. (2021). The Image of Work and the Ideal Leadership in Shuju Kokoroegusa - The Manual of Master and Servant. Romanian Economic and Business Review, 15(4), 35-51.

Yamaguchi, B., Takahashi, T., Vlad, C., Kaneko, H. \& Damaschin, A. (2020). The Impact of Resource-Based Circular Economic Models in Japan. Romanian Economic and Business Review, 15(2), 7-29. 